\title{
Synthesis and Structures of Vanadium(III) and -(IV) Complexes with a Tripodal Quadridentate Ligand Containing Alcoholic and Pyridyl or Imidazolyl Functionality
}

\author{
Kan Kanamori*, ${ }^{1}$, Kazuya Fujimoto ${ }^{1}$, Eiji Yoneda ${ }^{1}$, Taeko Yokoyama ${ }^{1}$, Honoh Suzuki ${ }^{1}$, Koichi No- \\ zaki $^{1}$, Yoshitaro Miyashita ${ }^{2}$ and Ken-Ichi Okamoto ${ }^{2}$ \\ ${ }^{1}$ Department of Chemistry, Graduate School of Science and Engineering, University of Toyama, 3190 Gofuku, Toyama \\ 930-8555, Japan \\ ${ }^{2}$ Department of Chemistry, Graduate School of Pure and Applied Sciences, University of Tsukuba, 1-1-1 Tennodai, \\ Tsukuba 305-8571, Japan
}

\begin{abstract}
Complexes of vanadium(III) and vanadium(IV) were synthesized with the tripodal quadridentate ligands, $N, N$ bis(2-pyridylmethyl)-2-aminoethanol (Hbpmae) and $N, N$-bis(2-imidazolylmethyl)-2-aminoethanol (Hbimae). The chemical structures and geometries were determined by X-ray crystallography or spectral measurements. Vanadium(III) formed structurally similar, oxo-bridged, dinuclear complexes with both ligands and exhibited intense absorption bands in the visible region. Upon exposure to air, the vanadium(III) complexes oxidized spontaneously, yielding the respective vanadium(IV) complexes. The geometry of the vanadium(IV)-Hbpmae complex was very similar to that of the monomeric unit in the corresponding vanadium(III) dimer. The alkoxo group in all four complexes coordinated to a metal center in a protonated form. The geometrical arrangements of the vanadium(IV)-Hbpmae and -Hbimae complexes were different with each other. The intense absorption bands in the visible region of the oxo-bridged dinuclear vanadium(III) complexes were assigned based on molecular orbital calculation.
\end{abstract}

Keywords: Charge-Transfer Transition, Molecular Orbital Calculation, Vanadium(III) and -(IV) Complexes, X-ray Structure

\section{INTRODUCTION}

Certain species of ascidians are known to accumulate vanadium from seawater selectively and intensively.[1]. Vanadium accumulated is reduced to the +III oxidation state and stored in vacuoles of vanadocytes (vanadium-containing blood cells). However, the physiological function of vanadium(III) in ascidian blood cells has not yet been clarified. In order to understand the role of vanadium(III) in ascidians, we have studied the development of coordination chemistry of vanadium(III) in details.

The structure of a vanadium(III) complex depends highly on the chemical structure of the ligands, the chelate ring size and the nature of the coordinating groups. For example, hexadentate amino polycarboxylate ligands such as ethylenediamine- $N, N, N^{\prime}, N^{\prime}$-tetraacetate (edta) [2] and quadridentate amino polycarboxylate ligands such as nitrilotriacetate (nta) [3], form solely five-membered chelate rings, yielding heptacoordinate vanadium(III) complexes. Conversely, the ligands that form six-membered chelate rings such as 1,3propanediamine- $N, N, N^{\prime}, N^{\prime}$-tetraacetate (1,3-pdta) [4] and $N, N$-bis(carboxymethyl)- $\beta$-alanate ( $\beta$-alada) [5] yield hexacoordinate mononuclear vanadium(III) complexes. Hexacoordinate mononuclear vanadium(III) produces an oxobridged dinuclear complex upon base hydrolysis, whereas heptacoordinate vanadium(III) complexes do not $[5,6]$. In acidic solution, the substitution of acetate group(s) in nta by

*Address correspondence to this author at the Department of Chemistry, Graduate School of Science and Engineering, University of Toyama, 3190 Gofuku, Toyama 930-8555, Japan; Tel/Fax: +81 76445 6609;

E-mail: kanamori@sci.u-toyama.ac.jp 2-pyridylmethyl group(s) results in the formation of a hexacoordinate mononuclear species. In basic solution, an oxobridged dinuclear complex is formed, as observed in 1,3-pdta and $\beta$-alada complexes [7]. An oxo-bridged dinuclear structure has also been observed in a complex that has a tridentate ligand containing an imidazolylmethyl group (histidine) $[8,9]$. However, the substitution of two acetate groups in edta by two 2-pyridylmethyl groups produces a heptacoordinate mononuclear complex [10]. These studies suggest that the introduction of pyridyl functional groups into a polydentate ligand does not necessarily yield oxo-bridged dinuclear complexes.

The replacement of an acetate group in nta [11] or edta [12] by a hydroxyethyl group (as opposed to a pyridylmethyl group) results in the formation of dialkoxo-bridged dinuclear complexes. Therefore, it is of interest to determine the structural characteristics of vanadium(III) complexes formed with tripodal quadridentate ligands containing an alkoxo group and pyridylmethyl or imidazolylmethyl groups. Here, we report the synthesis, structural characterization, and spectroscopic analysis of vanadium(III) complexes with $N, N$-bis(2pyridylmethyl)-2-aminoethanol (Hbpmae) and $\mathrm{N}, \mathrm{N}$-bis(2imidazolylmethyl)-2-aminoethanol (Hbimae) (Scheme 1). The molecular structures of the corresponding vanadium(IV) complexes were examined for comparison.

\section{EXPERIMENTAL SECTION}

\subsection{Preparation of Ligands}

Hbpmae was prepared according to a previously published method [13]. Hbimae was similarly prepared by the 
above method, except that 4-imidazolecarboxaldehyde was substituted in place of 2-pyridinecarboxaldehyde.<smiles>OCCN(Cc1ccccn1)Cc1ccccn1</smiles>

Hbpmae<smiles>OCCN(Cc1cnc[nH]1)Cc1cnc[nH]1</smiles>

Hbimae
Scheme 1. Ligands.

\subsection{Preparation of Complexes}

All synthetic procedures involving vanadium(III) complexes were performed in an $\mathrm{N}_{2}$-filled glove box or in an $\mathrm{Ar}$ atmosphere using standard Schlenk techniques.

\subsection{1. $\left[\mathrm{V}^{\mathrm{III}}{ }_{2}(\mu-\mathrm{O}) \mathrm{Cl}_{2}(\mathrm{Hbpmae})_{2}\right] \mathrm{Cl}_{2} \cdot 3.5 \mathrm{H}_{2} \mathrm{O}$ (1)}

Vanadium(III) chloride $(0.21 \mathrm{~g} ; 1.3 \mathrm{mmol})$ was stirred into an aqueous solution (30 ml) of Hbpmae (0.31 g; 1.3 $\mathrm{mmol})$, resulting in a reddish brown solution. After evaporating to dryness, the resulting reddish purple solid was dissolved in $8 \mathrm{ml}$ of ethanol containing $0.1 \mathrm{ml}$ of water at 70 ${ }^{\circ} \mathrm{C}$. Reddish brown crystals $(0.20 \mathrm{~g}, 46 \%$ yield $)$ were formed by cooling the solution slowly. Elemental analysis: C, 42.49; $\mathrm{H}, 5.16 ; \mathrm{N}, 10.20 \%$. Calcd for $\mathrm{C}_{28} \mathrm{H}_{41} \mathrm{~N}_{6} \mathrm{O}_{6.5} \mathrm{~V}_{2} \mathrm{Cl}_{4}$ : C, 41.55; $\mathrm{H}, 5.11 ; \mathrm{N}, 10.38 \%$. Selected IR data ( $\mathrm{KBr}$ disk): 1607 , 1447, 1290, 1093, 1037, 1027, 992, 883, 802, 765, 727, 650 $\mathrm{cm}^{-1}$.

\subsection{2. [ $\left.\mathrm{V}^{\mathrm{IV}} \mathrm{OCl}(\mathrm{Hbpmae})\right] \mathrm{Cl}(2)$}

Barium chloride dihydrate $(0.24 \mathrm{~g} ; 1.0 \mathrm{mmol})$ was added to an aqueous solution $(5 \mathrm{ml})$ of Hbpmae $(0.24 \mathrm{~g} ; 1.0 \mathrm{mmol})$. This solution was then mixed with an aqueous solution ( 5 $\mathrm{ml})$ of $\operatorname{VOSO}_{4} \cdot 3 \mathrm{H}_{2} \mathrm{O}(0.23 \mathrm{~g} ; 1.0 \mathrm{mmol})$ and stirred for 1

Table 1. Summary of X-Ray Data Collection and Refinement

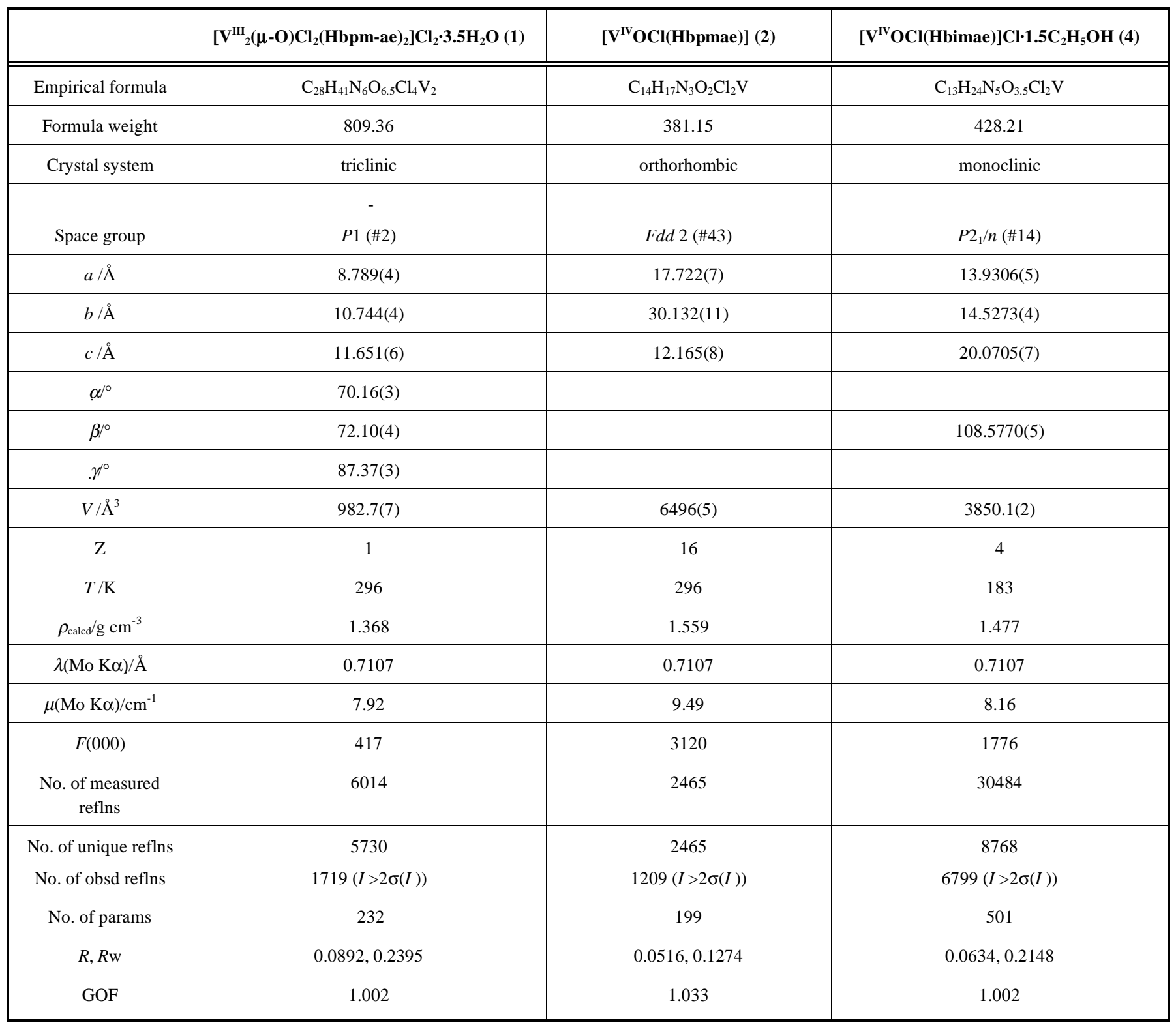


day. The barium sulfate precipitate was filtered off and the filtrate was evaporated to dryness. The blue powder thus obtained was dissolved in $7 \mathrm{ml}$ of methanol at $60{ }^{\circ} \mathrm{C}$. Slow cooling of the solution yielded blue crystals $(0.16 \mathrm{~g} ; 42 \%$ yield). The same compound was obtained by air oxidation of the corresponding vanadium(III) complex. Elemental analysis: $\mathrm{C}, 43.91 ; \mathrm{H}, 4.41 ; \mathrm{N}, 10.83 \%$. Calcd for $\mathrm{C}_{14} \mathrm{H}_{17} \mathrm{~N}_{3} \mathrm{O}_{2} \mathrm{VCl}_{2}$ : C, 44.12, H, 4.50; N, 11.03\%. Selected IR data (KBr disk): 1607, 1452, 1419, 1293, 1107, 1089, 1062, 1033, 971, 888, 802, 772, $730 \mathrm{~cm}^{-1}$.

\subsection{3. $\left[\mathrm{V}^{\mathrm{III}}{ }_{2}(\mu-\mathrm{O}) \mathrm{Cl}_{2}(\mathrm{Hbimae})\right] \mathrm{Cl}_{2} \cdot 0.5 \mathrm{C}_{2} \mathrm{H}_{5} \mathrm{OH} \cdot 2 \mathrm{H}_{2} \mathrm{O} \cdot 4 \mathrm{LiCl}$} (3)

Vanadium(III) chloride (0.16 g; $1.0 \mathrm{mmol})$ was dissolved in an aqueous solution of Hbimae $(0.22 \mathrm{~g} ; 1.0 \mathrm{mmol})$ and $\mathrm{LiOH} \cdot \mathrm{H}_{2} \mathrm{O}(0.02 \mathrm{~g} ; 0.5 \mathrm{mmol})$, producing a reddish brown solution. After evaporating to dryness, the reddish purple solid was dissolved in $5 \mathrm{ml}$ of ethanol and allowed to stand at room temperature. The precipitate was filtered, washed with ethanol, and dried in a vacuum desiccator, resulting in a reddish brown powder $(0.30 \mathrm{~g} ; 33 \%$ yield $)$. Further purification was unsuccessful because of significant oxidation. Elemental analysis: $\mathrm{C}, 27.43 ; \mathrm{H}, 4.40 ; \mathrm{N}, 15.23 \%$. Calcd for $\mathrm{C}_{21} \mathrm{H}_{40} \mathrm{~N}_{10} \mathrm{O}_{5.5} \mathrm{~V}_{2} \mathrm{Cl}_{8} \mathrm{Li}_{4}$ : C, 27.63; H, 4.41; N, 15.34\%. Selected IR data (nujol mull): 1378, 1270, 1081, 1048, 1009, $981,722 \mathrm{~cm}^{-1}$.

\subsection{4. [ $\left.\mathrm{V}^{\mathrm{IV}} \mathrm{OCl}(\mathrm{Hbimae})\right] \mathrm{Cl} \cdot 1.5 \mathrm{C}_{2} \mathrm{H}_{5} \mathrm{OH}$ (4)}

Vanadium(III)-Hbimae complex obtained by the above method was dissolved in $8 \mathrm{ml}$ of ethanol. Air oxidation of the complex resulted in a pale blue solution. The solution allowed to stand at $50{ }^{\circ} \mathrm{C}$, yielding pale blue crystals $(0.19 \mathrm{~g}$; $44 \%$ yield). The same compound was obtained with a lower yield by a reaction of $\mathrm{V}^{\mathrm{IV}} \mathrm{OSO}_{4}$ with Hbimae in a similar procedure as $\left[\mathrm{V}^{\mathrm{IV}} \mathrm{OCl}(\mathrm{Hbpmae})\right]$. Elemental analysis: $\mathrm{C}$, $32.17 ; \mathrm{H}, 4.33$; $\mathrm{N}, 18.54 \%$. Calcd for $\mathrm{C}_{10} \mathrm{H}_{17} \mathrm{~N}_{5} \mathrm{O}_{3} \mathrm{VCl}_{2}=$ $\left[\mathrm{V}^{\mathrm{IV}} \mathrm{OCl}(\right.$ Hbimae) $] \mathrm{Cl} \cdot \mathrm{H}_{2} \mathrm{O}: \mathrm{C}, 31.84 ; \mathrm{H}, 4.55 ; \mathrm{N}, 18.57 \%$. Since the crystals display significant efflorescence, ethanol molecules of crystallization, which were evident in the X-ray crystal structure, were exchanged with water molecules under air at room temperature. Selected IR data (KBr disk): 1502, 1461, 1345, 1270, 1104, 1080, 1016, 979, 800, 673, $618 \mathrm{~cm}^{-1}$

\subsection{Measurements}

UV-visible absorption spectra were measured using a Shimadzu UV-3100PC spectrophotometer. The spectra of vanadium(III) complexes were obtained in an Ar atmosphere. Infrared absorption spectra were recorded on a JASCO FT/IR-8000S. Magnetic susceptibility at $298 \mathrm{~K}$ was measured using Sherwood Scientific MSB-AUTO.

\subsection{X-Ray Structure Determination}

The crystallographic data are summarized in Table 1. A crystal of $\left[\mathrm{V}^{\mathrm{III}}(\mu-\mathrm{O}) \mathrm{Cl}_{2}(\mathrm{Hbpmae})_{2}\right] \mathrm{Cl}_{2} \cdot 3.5 \mathrm{H}_{2} \mathrm{O} \quad(\mathbf{1}), \quad\left[\mathrm{V}^{\mathrm{I}-}\right.$ $\left.{ }^{\mathrm{V}} \mathrm{OCl}(\mathrm{Hbpmae})\right] \mathrm{Cl}(2)$, or $\left[\mathrm{V}^{\mathrm{IV}} \mathrm{OCl}(\mathrm{Hbimae})\right] \mathrm{Cl} \cdot 1.5 \mathrm{C}_{2} \mathrm{H}_{5} \mathrm{OH}$ (4) was mounted on a glass fiber, coated with epoxy resin as a precaution against solvent loss, and centered on a Rigaku AFC7R (complex 1), a Rigaku AFC7S (complex 2), or a Rigaku Mercury CCD system (complex 4) using graphitemonochromated Mo K $\alpha$ radiation. Diffraction data on complexes 1 and 2 were collected at $23^{\circ} \mathrm{C}$. Crystals of complex
4, however, displayed significant efflorescence at room temperature in air, causing a loss of ethanol molecules of crystallization. Diffraction data for complex 4 were therefore obtained at $-90{ }^{\circ} \mathrm{C}$.

Structural data were obtained using the direct methods SIR2004 [14] for complexes 1 and 4, and SHELX97 [15] for complex 2. Some remaining atom positions were found by successive Fourier techniques, DIRDIF99 [16]. All of the non-hydrogen atoms were refined anisotropically. Hydrogen atoms, except those of water, were included but not refined. All calculations were performed using CrystalStructure $[17,18]$ for complexes 1 and $\mathbf{4}$, and SHELX97 for complex 2 [15]. Crystallographic data were deposited with Cambridge Crystallographic Data Centre: deposition numbers 671279671281. Copies of the data can be obtained free of charge via http://www.ccdc.cam.ac.uk/conts/retreiving.html (or from the Cambridge Crystallographic Data Centre, 12, Union Road, Cambridge, CB2 1EZ, UK: fax: +44 1223 336033; email: deposit@ccdc.ccam.ac.uk ).

\subsection{Theoretical Calculations}

Electronic structure calculations of complex 1 were carried out using the X-ray structure at a density functional theory (DFT) level with Gaussian 98, revision A 11.3 [19]. A density functional of Becke's style three-parameter hybrid functional for the Perdew-Wang exchange-correlation (B3PW91) was used [20]. The basis functions used were Dunning-Hay's split-valence double- $\zeta$ for $\mathrm{C}, \mathrm{H}$, and $\mathrm{N}$ atoms (D95) and the Hay-Wadt double- $\zeta$ with a Los Alamos relativistic effective core potential for $\mathrm{V}$ and $\mathrm{Cl}$ atoms (LANL2DZ) [21]. Energies and properties for electronic excitations were calculated at a time-dependent DFT level using the B3PW91 functional. The molecular orbitals were drawn using MOLEKEL [22]

\section{RESULTS AND DISCUSSION}

\subsection{Structural Description of Complex 1}

A perspective view of the cationic part of complex $\mathbf{1}$ is shown in Fig. (1), and the selected bond distances and angles are summarized in Table $\mathbf{2}$. The X-ray crystal structure revealed that complex $\mathbf{1}$ is a single oxo-bridged dinuclear complex with a crystallographically enforced center of symmetry on the bridging oxo atom. Although such a strictly linear V(III)-O-V(III) bridging mode has been observed in $\left[\mathrm{V}_{2}^{\mathrm{III}}{ }_{2} \mathrm{O}\left(\mathrm{NH}_{3}\right)_{10}\right] \mathrm{I}_{4}[23]$, the $\mathrm{V}(\mathrm{III})-\mathrm{O}-\mathrm{V}(\mathrm{III})$ moiety usually takes a slightly bent configuration because of some weak inter- and/or intramolecular interactions such as $\pi-\pi$ stacking $[24,25]$ and hydrogen bond formation $[8,9]$. In a mononuclear unit, the vanadium(III) center adopts a distorted octahedral geometry. The two pyridyl nitrogen atoms of the quadridentate Hbpmae ligand are bound to the vanadium(III) center in a trans configuration. This coordination mode results in a fairly small trans angle (N2-V1-N3: 159.2(3) $)^{\circ}$ compared with the ideal trans angle of an octahedron $\left(180^{\circ}\right)$. The alkoxo oxygen atom is situated in the trans position of the bridging oxo atom. Consideration of the charge balance of complex 1 indicates that the alkoxo groups of the ligand coordinate to vanadium(III) in a protonated form (Hbpmae). The V-O(alcohol) distances support this speculation. The V1-O2 bond length (2.141(10) $\AA$ ) is greater by $0.1-0.15 \AA$ than that of the coordination bond length of a deprotonated 


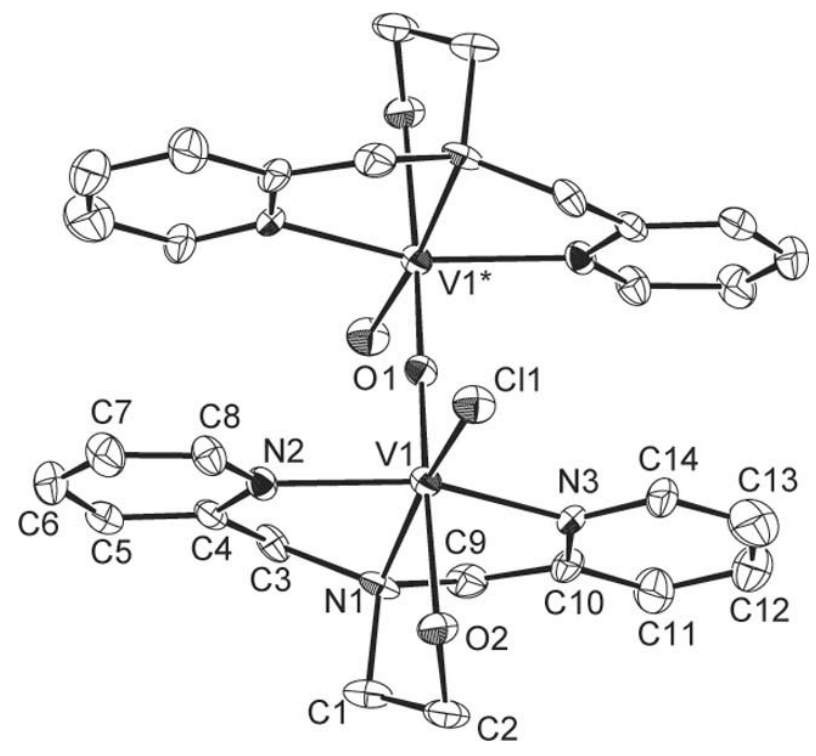

Fig. (1). Perspective View of the Cationic Part of Complex 1.

alkoxo group [11, 12], reflecting weak coordination by the protonated alkoxo group. The sixth coordination position is occupied by a chloro ligand. The bond length between the vanadium(III) center (V1) and the bridging oxo atom (O1) in complex 1 compares well with the corresponding bond lengths of other hexacoordinate oxo-bridged dinuclear vanadium(III) complexes [7, 23, 24, 26]. The bond length(s) between the vanadium(III) center and the amino nitrogen or pyridyl nitrogen atoms in complex $\mathbf{1}$ also agree well with those found in the hexacoordinate oxo-bridged dinuclear vanadium(III) complex, $\left[\mathrm{V}_{2}^{\mathrm{III}}(\mu-\mathrm{O}) \mathrm{Br}_{2}(\mathrm{tpa})_{2}\right]^{2+}$ (tpa: tris $(2-$ pyridylmethyl)amine) [7], but are slightly shorter than those found in the heptacoordinate mononuclear vanadium(III) complex, $\quad\left[\mathrm{V}^{\mathrm{III}}(\text { bpedda })\left(\mathrm{H}_{2} \mathrm{O}\right)\right]^{+} \quad$ (bpedda: N,N'-bis(2pyridylmethyl)-1,2-ethanediaimine- $N, N^{\prime}$-diacetate) [10], reflecting a lower coordination number (six vs. seven).

The coordination stereochemistry of vanadium(III) complexes depends highly on the coordinating group chemistry and chelate ring sizes [27]. In vanadium(III)-Hbpmae complex, the pyridyl group is more likely to induce the formation of an oxo-bridged dinuclear complex by base hydrolysis than the alkoxo group is of a dialkoxo-bridged dinuclear complex. It is possible that $\pi$ accepting character of the pyridyl group may have compensated an increase in electron density of vanadium(III) center induced by coordination of an oxo group with $\pi$ donating character.

Table 2. Selected Bond Distances $(\stackrel{\AA}{)})$ and Angles $\left(^{\circ}\right)$ for $\left[\mathrm{V}_{2}^{\mathrm{III}}(\mu-\mathrm{O}) \mathrm{Cl}_{2}\left(\mathrm{Hbpmae}_{2}\right] \mathrm{Cl}_{2} \cdot 3.5 \mathrm{H}_{2} \mathrm{O}(1)\right.$ and $\left[\mathrm{V}^{\mathrm{IV}} \mathrm{Cl}(\mathrm{Hbpmae})\right] \mathrm{Cl}(2)$

\begin{tabular}{|c|c|c|c|}
\hline V1-Cl1 & $2.365(3)$ & V1-Cl1 & $2.327(2)$ \\
\hline V1-O2 & $2.141(10)$ & V1-O2 & $2.202(5)$ \\
\hline V1-N1 & $2.137(7)$ & V1-N1 & $2.101(6)$ \\
\hline V1-N3 & $2.088(9)$ & V1-N3 & $2.117(7)$ \\
\hline Cl1-V1-O1 & $101.34(13)$ & Cl1-V1-O1 & $103.6(2)$ \\
\hline $\mathrm{Cl1}-\mathrm{V} 1-\mathrm{O} 2$ & $87.1(2)$ & Cl1-V1-O2 & $84.30(16)$ \\
\hline Cl1-V1-N1 & $165.6(3)$ & Cl1-V1-N1 & 160.87(19) \\
\hline O1-V1-N1 & $93.0(3)$ & O1-V1-N1 & $95.4(3)$ \\
\hline $\mathrm{O} 1-\mathrm{V} 1-\mathrm{N} 2$ & $93.2(3)$ & O1-V1-N2 & $94.9(3)$ \\
\hline O1-V1-N3 & $89.7(3)$ & O1-V1-N3 & $95.1(3)$ \\
\hline $\mathrm{O} 2-\mathrm{V} 1-\mathrm{N} 1$ & $78.6(4)$ & O2-V1-N1 & $76.7(2)$ \\
\hline $\mathrm{O} 2-\mathrm{V} 1-\mathrm{N} 2$ & $89.9(4)$ & $\mathrm{O} 2-\mathrm{V} 1-\mathrm{N} 2$ & $82.0(3)$ \\
\hline $\mathrm{O} 2-\mathrm{V} 1-\mathrm{N} 3$ & $84.2(3)$ & $\mathrm{O} 2-\mathrm{V} 1-\mathrm{N} 3$ & $85.2(2)$ \\
\hline N1-V1-N2 & $79.2(3)$ & N1-V1-N2 & $79.7(3)$ \\
\hline N1-V1-N3 & $80.1(3)$ & N1-V1-N3 & $78.2(3)$ \\
\hline
\end{tabular}




\subsection{Solution Properties of Complex 1}

Diffuse reflectance (powder) and absorption (ethanol solution) spectra of complex $\mathbf{1}$ are shown in Fig. (2). The spectra correspond well with each other, indicating that the solid-state structure was maintained upon dissolution in ethanol. The very intense absorption bands observed in the visible region for the known oxo-bridged dinuclear vanadium(III) complexes (for complex 1, the band at $518 \mathrm{~nm}$ with $\varepsilon=2990 \mathrm{~mol}^{-1} \mathrm{dm}^{3} \mathrm{~cm}^{-1}$ ) have been assigned to the ligand-to-metal charge transfer (LMCT) transition of the V(III)-O-V(IIII) moiety based on resonance Raman studies $[9,28-30]$. This assignment is discussed in greater detail later.

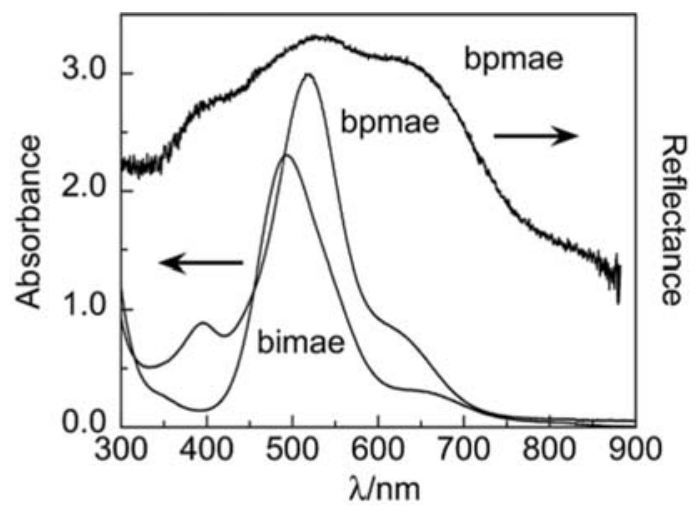

Fig. (2). Diffuse Reflectance and Absorption Spectra of complex 1 and Absorption Spectrum of Complex 3, both in Ethanol (1.0 mM).

Complex 1 was moderately stable in the crystalline state, yet was sensitive to air oxidation in solution. The LMCT absorption band at $518 \mathrm{~nm}$ completely disappeared after 150 min in ethanol under aerobic conditions, yielding a light blue solution. This color change suggested the oxidation of vanadium(III) to vanadium(IV). The X-ray crystal structure of this resulting vanadium(IV) complex (2) was determined to obtain structural data that may explain the instability of complex 1.

\subsection{Structural Description of Complex 2}

A perspective view of the cationic part of complex $\mathbf{2}$ is shown in Fig. (3). The selected bond distances and angles are stated in Table 2, along with those of complex $\mathbf{1}$. The vanadium(IV) atom has a distorted octahedral structure. On the whole, the coordination geometry of complex $\mathbf{2}$ is very similar to that of the mononuclear unit in complex 1, except that the bridging oxo atom in complex 1 replaces the terminal oxo atom in complex $\mathbf{2}$. The alkoxo group in complex $\mathbf{2}$ also coordinates to vanadium(IV) in a protonated form as in complex 1. A similar coordination mode of alkoxo groups has been observed in $\left[\mathrm{V}^{\mathrm{IV}} \mathrm{O}\left(\mathrm{OH}_{2}\right)(\right.$ Hhida) $]$ (Hhida: $N-(2-$ hydroxyethyl)iminodiacetate) [31]. The alcohol oxygen of complex 2 is situated in a trans position to the oxo group, whereas that in the Hhida complex is in a cis position. As a result of the strong trans influence of the oxo group, the $\mathrm{V}(\mathrm{IV})-\mathrm{O}$ (alcohol) distance is longer in complex $\mathbf{2}(2.202(5)$ $\AA$ ) than in the Hhida complex (2.070(5) $\AA$ ). The short V1-O1 distance $(1.604(6) \AA)$ indicates considerable $\pi$-bond character. The differences in other coordination bond lengths between complex $\mathbf{1}$ and complex $\mathbf{2}$ are relatively small despite a reduction in the ionic radius of vanadium by $0.06 \AA$ as a result of oxidation from III to IV [32]. The bond angles in complex 2 also compare well with the corresponding angles in complex 1. This small rearrangement of atomic positions, i.e., a small energetic barrier to oxidation, may be one of the reasons that complex $\mathbf{1}$ is easily oxidized to complex, $\mathbf{2}$.

\subsection{Structural Estimation and Properties of Complex 3}

We evaluated the changes in structural and spectroscopic properties caused by the substitution of the pyridyl groups in Hbpmae by the imidazole groups in Hbimae. The coordination chemistry of imidazole groups is of importance in bioinorganic chemistry because imidazole groups are biologically relevant heterocyclic compounds. The molecular structure of complex 3 was based on the visible absorption spectrum and elemental analysis, because crystals of complex $\mathbf{3}$ were not attainable with sufficient quality for X-ray crystallography.

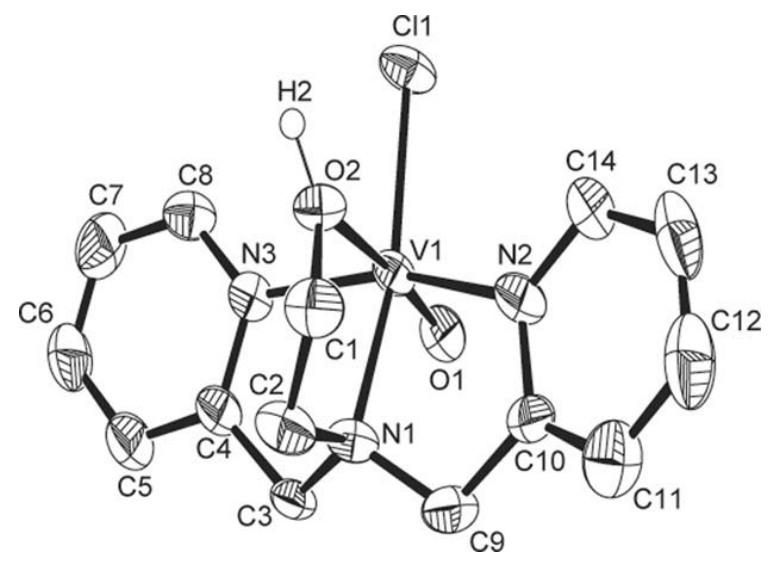

Fig. (3). Perspective View of the Cationic Part of Complex 2.

The absorption spectra of complexes $\mathbf{1}$ and $\mathbf{3}$ are very similar (Fig. 2). The LMCT transition of the V(III)-O-V(III) moiety at $494 \mathrm{~nm}$ indicates that complex 3 also has an oxobridged dinuclear structure. The elemental analysis and charge balance suggests that the alkoxo group in complex $\mathbf{3}$ is coordinated to the vanadium(III) center in a protonated form as observed in complex $\mathbf{1}$.

Complex 3 was extremely labile toward oxidation upon exposure to air in both solution and solid powder form. When exposed to air, powder sample of complex $\mathbf{3}$ changed from reddish brown to light blue within $12 \mathrm{~h}$, indicative of the oxidation of vanadium(III) to vanadium(IV). In an aerobic ethanol solution, the LMCT band completely disappeared after $1 \mathrm{~h}$, presumably attributable to the formation of vanadium(IV) complex. This oxidation reaction is much faster than in complex 1, suggesting that the substitution of pyridyl groups in Hbpmae with imidazolyl groups resulted in the destabilization of the vanadium(III) complex.

\subsection{Structure and Properties of Complex 4}

The perspective view of $\left[\mathrm{V}^{\mathrm{IV}} \mathrm{OCl}(\mathrm{Hbimae})\right]^{+}$is shown in Fig. (4), and the selected bond distances and angles are summarized in Table 3. The unit cell of the crystal contains two crystallographically independent complex ions with similar geometries. Complex $\mathbf{4}$ has a distorted octahedral structure composed of a quadridentate Hbimae ligand, a 


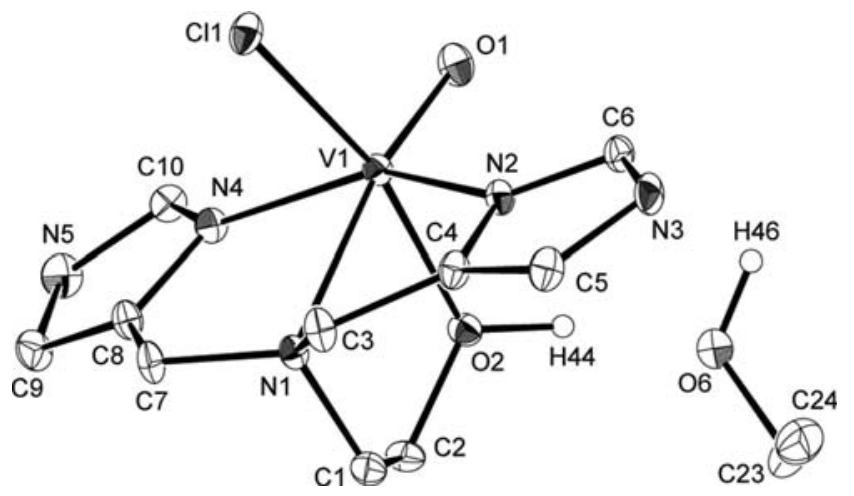

Fig. (4). Perspective View of the Cationic Part of Complex 4.

chloro ligand, and an oxo ligand. As observed in complexes 1-3, the alkoxo group coordinates to the vanadium(IV) center in a protonated form. The coordination arrangement of the Hbimae ligand is similar to that of Hbpmae in complex 2 with the two imidazole groups occupying trans positions relative to each other. The trans angle in complex 4 (av. $\left.148.51(14)^{\circ}\right)$ is significantly smaller than the corresponding angle in complex $2\left(156.4(3)^{\circ}\right)$. Interestingly, the positions of the chloro and oxo ligands in complex 4 were interchanged relative to their positions in complex $\mathbf{2}$, i.e., the oxo ligand is positioned trans to the amino nitrogen in complex 4, whereas it is positioned trans to the chloro ligand in complex 2. This considerably weakens the coordination bond strength of the amino nitrogen (N1) in complex 4 because of the strong trans influence of the oxo ligand. The net result is manifest in a lengthening of the V1-N1 bond distance in complex 4 (av. 2.365(3) A) relative to the corresponding bond length in complex 2 (2.101(6) $\AA$ ). Additionally, the bond length between the vanadium(IV) atom and the alkoxo oxygen is shortened in complex 4 (av. 2.083(2) $\AA$ ) relative to that in complex $2(2.202(5) \AA)$. If we assume that the vanadium(III) complex with Hbimae (complex 3) has an identical donor atom arrangement as complex $\mathbf{4}$, then the exchange of positions between the bridging oxo atom and the chloro atom in complex $\mathbf{1}$ relative to complex $\mathbf{3}$ may also help to explain the observed difference in the stability of the two vanadium(III) complexes.

\subsection{Assignment of the Intense Visible Band}

Oxo-bridged dinuclear vanadium(III) complexes exhibit an intense band in the $400-550 \mathrm{~nm}$ region as observed in ethanol solution of complex $\mathbf{1}$. Based on the resonance Raman studies, this intense band was assigned to a charge transfer transition between the bridging oxo atom and vanadium(III) atom [9, 28-30]. A qualitative molecular orbital

Table 3. Selected Bond Distances $(\AA)$ and Angles $\left({ }^{\circ}\right)$ for $\left[\mathrm{V}^{\mathrm{IV}} \mathrm{OCl}(\mathrm{Hbimae})\right] \mathrm{Cl} \cdot 1.5 \mathrm{C}_{2} \mathrm{H}_{5} \mathrm{OH}$

\begin{tabular}{|c|c|c|c|}
\hline V1-Cl1 & $2.3291(11)$ & $\mathrm{V} 2-\mathrm{Cl} 2$ & $2.3353(13)$ \\
\hline $\mathrm{V} 1-\mathrm{O} 2$ & $2.089(2)$ & $\mathrm{V} 2-\mathrm{O} 4$ & $2.076(3)$ \\
\hline V1-N1 & $2.355(3)$ & V2-N6 & $2.375(3)$ \\
\hline V1-N2 & $2.082(3)$ & V2-N7 & $2.091(3)$ \\
\hline Cl1-V1-O1 & $101.94(11)$ & $\mathrm{Cl} 2-\mathrm{V} 2-\mathrm{O} 3$ & $101.63(12)$ \\
\hline $\mathrm{Cl1}-\mathrm{V} 1-\mathrm{O} 2$ & $165.42(9)$ & $\mathrm{Cl} 2-\mathrm{V} 2-\mathrm{O} 4$ & $165.13(8)$ \\
\hline Cl1-V1-N1 & $88.95(8)$ & $\mathrm{Cl} 2-\mathrm{V} 2-\mathrm{N} 6$ & $90.25(8)$ \\
\hline Cl1-V1-N2 & 88.81(9) & $\mathrm{Cl} 2-\mathrm{V} 2-\mathrm{N} 7$ & $89.12(10)$ \\
\hline O1-V1-N1 & $168.91(14)$ & O3-V2-N6 & $168.04(14)$ \\
\hline O1-V1-N2 & $104.40(16)$ & O3-V2-N7 & $105.29(16)$ \\
\hline O1-V1-N4 & $106.51(15)$ & O3-V2-N9 & $106.27(18)$ \\
\hline $\mathrm{O} 2-\mathrm{V} 1-\mathrm{N} 1$ & $76.92(11)$ & O4-V2-N6 & 75.11(11) \\
\hline $\mathrm{O} 2-\mathrm{V} 1-\mathrm{N} 2$ & $90.57(12)$ & O4-V2-N7 & 89.11(14) \\
\hline $\mathrm{O} 2-\mathrm{V} 1-\mathrm{N} 4$ & $83.88(13)$ & O4-V4-N9 & $85.72(14)$ \\
\hline N1-V1-N2 & $73.41(12)$ & N6-V2-N7 & $73.23(12)$ \\
\hline
\end{tabular}


diagram for the $\mathrm{V}$ (III)-O-V(III) moiety was proposed by Bond et al. [28]. To obtain further insight on the intense band of the oxo-bridged dinuclear vanadium(III) complexes, a detailed molecular orbital diagram for vanadium(III)Hbpmae (complex 1) was calculated. The effective magnetic moment of complex 1 at $298 \mathrm{~K}$ is $3.06 \mu_{\mathrm{B}}$, which is larger than the spin-only value for $\mathrm{d}^{2}\left(2.83 \mu_{\mathrm{B}}\right)$, indicating a ferromagnetic coupling between two vanadium(III) centers. Thus, the ground state of complex $\mathbf{1}$ is reasonably assumed to be $S=5$.

A dinuclear complex containing a linear M-O-M moiety ( $\mathrm{M}=$ ruthenium(IV), rhenium, tungsten, and vanadium(III)) with a $D_{4 h}$ point group exhibit strong interaction between the metal $\mathrm{d}_{\mathrm{xy}}, \mathrm{d}_{\mathrm{yz}}$, and $\mathrm{d}_{\mathrm{zx}}$ orbitals, and oxygen $\mathrm{p}_{\mathrm{x}}$ and $\mathrm{p}_{\mathrm{y}}$ orbitals, yielding molecular orbitals (MOs) with the order $\mathrm{e}_{\mathrm{u}}<\left(\mathrm{b}_{2 \mathrm{~g}}\right.$, $\left.\mathrm{b}_{1 \mathrm{u}}, \mathrm{e}_{\mathrm{g}}\right)<\mathrm{e}_{\mathrm{u}}{ }^{*}$, where $\mathrm{e}_{\mathrm{u}}$ is bonding $\mathrm{d}_{\mathrm{zx}}-\mathrm{p}_{\mathrm{x}}-\mathrm{d}_{\mathrm{zx}}$ and $\mathrm{d}_{\mathrm{yz}}-\mathrm{p}_{\mathrm{y}}-\mathrm{d}_{\mathrm{yz}}$ MOs and $\mathrm{e}_{\mathrm{u}} *$ is the corresponding antibonding MO. The or-

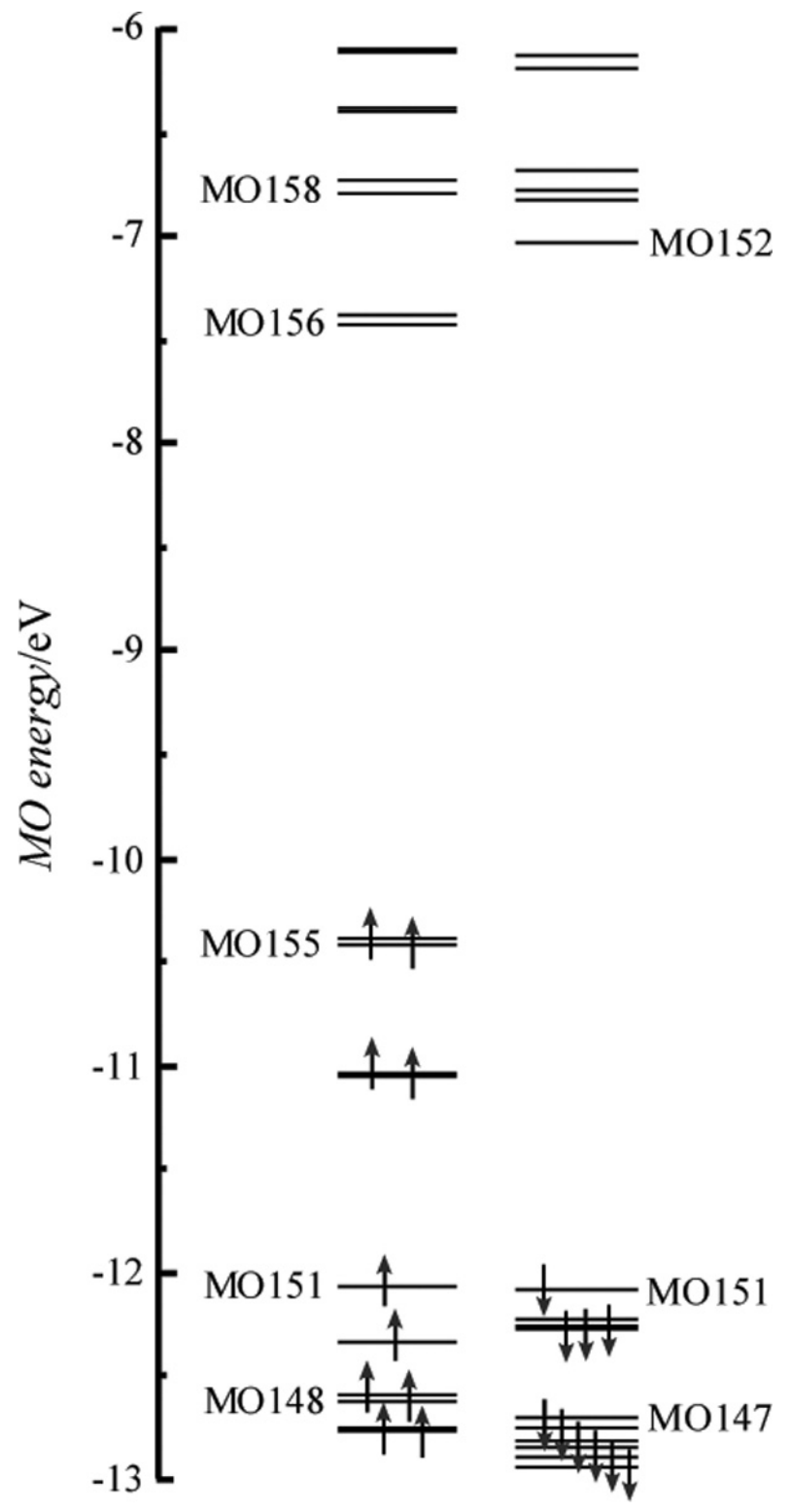

Fig. (5). Molecular Orbital Energy Diagram Calculated for Complex1 at the Unrestricted B3PW91/LANL2DZ Level. bitals in parentheses are approximately degenerate nonbonding MOs $[28,33,34]$. Transition moment calculations indicate that the intense transition in the visible region is ascribable to the $\mathrm{e}_{\mathrm{g}} \rightarrow \mathrm{e}_{\mathrm{u}}{ }^{*}$, a metal-localized $\pi \pi^{*}$-like transition within M-O-M moiety [34, 35]

DFT calculations for complex $\mathbf{1}$ also indicate that the intense visible band originates from the $\mathrm{e}_{\mathrm{g}} \rightarrow \mathrm{e}_{\mathrm{u}}{ }^{*}$ transition. Fig. (5) shows the energy diagram of MOs for complex 1 calculated at an unrestricted DFT level with an excess of four alpha-spin electrons, i.e., $S=5$. The unrestricted model uses separate spatial orbitals for the alpha-spin and beta-spin electrons. Features of alpha-spin electrons are shown in Fig. (5). Whereas the interaction of the V(III)-O-V(III) moiety with the Hbpmae ligands complicates the electronic structure, it is readily observed that unoccupied MO156 and MO157 MOs correspond to $\mathrm{e}_{\mathrm{u}}{ }^{*}$ and occupied MO154 and MO155 MOs are $e_{g}$. The other nonbonding MOs, i.e., $b_{1 g}$ and $\mathrm{b}_{2 \mathrm{u}}$, are MO152 and MO153, respectively. MO158 and MO159 are $\pi^{*}$ orbitals mainly on the Hbpmae ligands. MO148-MO151 MOs result from a combination of nonbonding 3p orbitals on the chloride ions. MO146-MO147 MOs are composed of $\pi$ orbitals of the pyridyl moieties and $3 \mathrm{p}(\mathrm{Cl})$ orbitals.

Table 4 summarizes the excitation energies and oscillator strengths $(f)$ of the low-lying 20 electronic transitions for complex 1. Transition 12 exhibits the greatest $f$ value at 2.57 $\mathrm{eV}(f=0.180,482 \mathrm{~nm})$, corresponding to the intense band observed at approximately 520nm in Fig. (2). This transition results from the combination of two one-electron $\mathrm{e}_{\mathrm{g}} \rightarrow \mathrm{e}_{\mathrm{u}}$ * transitions in the V(III)-O-V(III) moiety: MO154 $\rightarrow$ MO157 and MO155 $\rightarrow$ MO156. Thus, the intense visible absorption band observed in ethanol solution of complex $\mathbf{1}$ is ascribed on a theoretical basis to a $\pi \pi^{*}$-like transition within the V(III)-O-V(III) moiety. Transitions 10 and 11, which exhibit relatively low oscillator strengths $(f=0.006+0.013)$ are located on the low-energy side of the intense visible band. These weak transitions are characterized as LMCT from degenerate MO152 and MO153 orbitals involving $3 \mathrm{p}(\mathrm{Cl})$ and $\pi$ (pyridine) orbitals to $\mathrm{e}_{\mathrm{u}}{ }^{*}$ of the $\mathrm{V}(\mathrm{III})-\mathrm{O}-\mathrm{V}(\mathrm{III})$ moiety (MO157).

In previous work [29], the Raman band due to an antisymmetric V-O-V stretching mode was strongly resonanceenhanced upon excitation on the low-energy side of the intense visible absorption band. Because TD-DFT calculations indicate that this intense band is caused by the nondegenerate transition 12 (Table 4), it is unlikely that the excited state that is formed by the excitation of the intense band undergoes Jahn-Teller distortion. However, the LMCT transitions 10 and 11 are almost degenerate because of very weak electronic interactions with $3 p$ orbitals of the chloride ions. Therefore, excitation into the LMCT band is most likely to cause localization of the excited state on one of the V(III)-Cl moieties. Because the localization is accompanied by the Jahn-Teller distortion breaking the point symmetry of the V$\mathrm{O}-\mathrm{V}$ moiety, the LMCT excitation would be coupled to an antisymmetric $\mathrm{V}-\mathrm{O}-\mathrm{V}$ stretching mode. Thus, this coupling would induce a strong enhancement in the antisymmetric Raman V-O-V stretching mode in oxo-bridged dinuclear vanadium(III) complexes. 

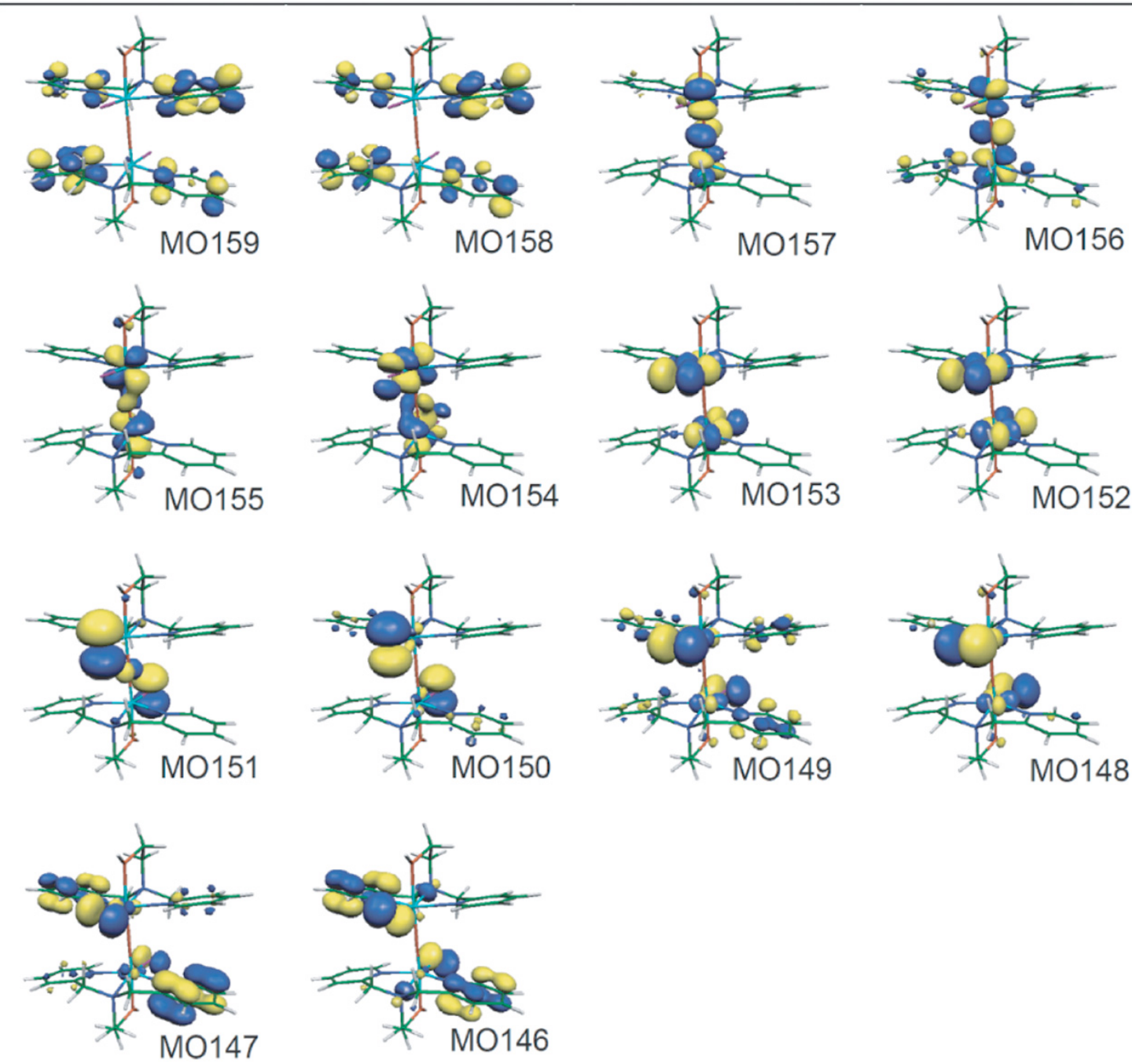

Fig. (6). Molecular Orbitals for Alpha-spin Electrons Calculated for Complex 1 at the Unrestricted B3PW91/LANL2DZ level.

Table 4. Calculated Excitation Energies, Oscillator Strengths ( $f$ in Parentheses), and Major Electronic Configurations for Complex 1

\begin{tabular}{|c|c|c|c|c|}
\hline 1 & 0.338 & $154 \rightarrow 157$ & $155 \rightarrow 156$ & \\
\hline 2 & 0.691 & $154 \rightarrow 156$ & $155 \rightarrow 157$ & \\
\hline 3 & 1.150 & $154 \rightarrow 156$ & $155 \rightarrow 157$ & \\
\hline 4 & 1.206 & $152 \rightarrow 156$ & $153 \rightarrow 157$ & \\
\hline 5 & 1.229 & $152 \rightarrow 157$ & $153 \rightarrow 156$ & $153 \rightarrow 157$ \\
\hline 8 & $2.447(0.001)$ & $153 \rightarrow 167$ & & \\
\hline 9 & 2.454 & $152 \rightarrow 167$ & $153 \rightarrow 168$ & \\
\hline 10 & $2.480(0.006)$ & $152 \rightarrow 157$ & $153 \rightarrow 156$ & \\
\hline 11 & $2.493(0.013)$ & $152 \rightarrow 157$ & $153 \rightarrow 157$ & \\
\hline 12 & $2.570(0.180)$ & $154 \rightarrow 157$ & $155 \rightarrow 156$ & \\
\hline
\end{tabular}




\section{CONCLUSIONS}

Vanadium(III) and -(IV) complexes with a tripodal quadridentate ligand containing an alkoxo group and two pyridyl (or imidazolyl) groups were prepared and structurally characterized by X-ray crystallography and/or spectroscopic analysis. The vanadium(III) complexes had an oxobridged dinucler structure, indicating that the pyridyl or imidazolyl group is more likely to induce the formation of an oxo-bridged dinuclear complex than the alkoxo group is of a dialkoxo-bridged dinuclear complex. The alkoxo group coordinated in a protonated form for both vanadium(III) and (IV) complexes. The vanadium(III) complexes were very labile toward air oxidation, yielding the corresponding vanadium(IV) complexes. The intense visible absorption band and the low-energy shoulder band of complex 1 were assigned to a $\pi \pi^{*}$-like transition within the $\mathrm{V}(\mathrm{III})-\mathrm{O}-\mathrm{V}(\mathrm{III})$ moiety and an LMCT transition from $3 \mathrm{p}(\mathrm{Cl})$ and $\pi$ (pyridine) orbitals to the V(III)-O-V(III) moiety, respectively, based on theoretical calculations.

\section{ACKNOWLEDGEMENT}

The authors thank Dr. Sumio Kaizaki (Osaka University) for magnetic measurement.

\section{REFERENCES}

[1] Michibata, H.; Yamaguchi, N.; Uyama, T.; Ueki, T. Coord. Chem., Rev. 2003, 237, 41 .

[2] (a) Shimoi, M.; Saito, Y.; Ogino, H. Chem. Lett., 1989, $18,1675$. (b) Shimoi, M.; Saito, Y.; Ogino, H. Bull. Chem. Soc. Jpn., 1991, 64, 2629.

[3] Okamoto, K.; Hidaka, J.; Fukagawa, M.; Kanamori, K. Acta Cryst., 1992, C48, 1025.

[4] Robles, J.C.; Matsuzaka, Y.; Inomata, S.; Shimoi, M.; Mori, W.; H. Ogino, H. Inorg. Chem., 1993, 32, 13.

[5] Kanamori, K.; Kumada, J.; Yamamoto, M.; Okayasu, T.; Okamoto, K. Bull. Chem. Soc. Jpn., 1995, 68, 3445.

[6] Kanamori, K.; Ino, K.; Maeda, H.; Miyazaki, K.; Fukagawa, M.; Kumada, J.; Eguchi,T.; Okamoto, K. Inorg. Chem., 1994, 33, 5547.

[7] Kanamori, K.; Kameda, E.; Kabetani, T.; Suemoto, T.; Okamoto, K.; Kaizaki, S. Bull. Chem. Soc. Jpn., 1995, 68, 2581.

[8] Kanamori, K.; Teraoka, M.; Maeda, H.; Okamoto, K. Chem. Lett., 1993, 22, 1731.

[9] Czenuszewicz, R.S.; Yan, Q.; Bond, M.R.; Carrano, C.J. Inorg. Chem., 1994, 33, 6116.

[10] Kanamori, K.; Kyotoh, A.; Fujimoto, K.; Nagata, K.; Suzuki, H.; Okamoto, K. Bull. Chem. Soc. Jpn., 2001, 74, 2113.

[11] Kanamori, K.; Ishida, K.; Fujimoto, K.; Kuwai, T.; Okamoto, K. Bull. Chem. Soc. Jpn., 2001, 74, 2377.

[12] Shepherd, T.K.; Hatfield, W.E.; Ghosh, B.D.; Stout, C,D.; Kristine, F.J.; Ruble, J.R. J. Am. Chem. Soc., 1981, 103, 5511.

[13] Groves J.T.; Kady, I.O. Inorg. Chem., 1993, 32, 3868.

[14] SIR2004: Burla, M.C.; Caliandro, R.; Camalli, M.; Carrozzini, B.; Cascarano, G.L.; De Caro, L.; Giacovazzo, C.; Polidori, G.; Spagna, R. J. Appl. Crystallogr., 2005, 38, 381.
Sheldrick, G.M. SHELX97 Program for Crystal Structure Refinement from Diffraction Data; University of Göttingen: Göttingen, Germany, 1997.

[16] Beurskens, P.T.; Admiraal, G.; Beurskens, G.; Bosman, W.P.; de Gelder, R.; Israel, R.; Smits, J.M.M. The DIRDIF-99 program system, Technical Report of the Crystallography Laboratory; University of Nijmergen: The Netherlands, 1999.

[17] CrystalStructure 3.8, Crystal Structure Analysis Package; Rigaku and Rigaku/MSC: The Woodlands, TX, 2000-2006.

[18] Carruthers, J.R.; Rollett, J.S.; Betterridge, P.W.; Kinna, D.; Pearce, L.; Larsen, A.; Gabe, E. CRYSTALS Issue 11; Chemical Crystallography Laboratory: Oxford, UK, 1999.

[19] Frisch, M.J.; Trucks, G.W.; Schlegel, H.B.; Scuseria, G.E.; Robb, M.A.; Cheeseman, J.R.; Zakrzewski, V.G.; Montgomery, J.A.; Stratmann, R.E.; Burant, J.C.; Dapprich, S.; Millam, J.M.; Daniels, A.D.; Kudin, K.N.; Strain, M.C.; Farkas, O.; Tomasi, J.; Barone, V.; Cossi, M.; Cammi, R.; Mennucci, B.; Pomelli, C.; Adamo, C.; Clifford, S.; Ochterski, J.; Petersson, G.A.; Ayala, P.Y.; Cui, Q.; Morokuma, K.; Malick, D.K.; Rabuck, A.D.; Raghavachari, K.; Foresman, J.B.; Cioslowski, J.; Ortiz, J. V.; Stefanov, B.B.; Liu, G.; Liashenko, A.; Piskorz, P.; Komaromi, I.; Gomperts, R.; Martin, R.L.; Fox, D.J.; Keith, T.; Al-Laham, M.A.; Peng, C.Y.; Nanayakkara, A.; Gonzalez, C.; Challacombe, M.; Gill, P.M.W.; Johnson, B.G.; Chen, W.; Wong, M.W.; Andres, J.L.; HeadGordon, M.; Replogle, E.S.; Pople, J.A. Gaussian 98, revision A 11.3; Gaussian Inc.: Pittsburgh, PA, 1998.

[20] (a) Perdew, J. P. Phys. Rev. B, 1986, 33, 8822. (b) Perdew, J.P.; Burke, K.; Wang, Y. Phys. Rev. B, 1996, 54, 16533.

[21] (a) Dunning, T.H., Jr.; Hay, P.J. Modern Theoretical Chemistry, Vol. 3; Plenum: New York, 1976. (b) Hay, P.J.; Wadt, W.R. J. Chem. Phys., 1985, 82, 270; 284; 299.

[22] (a) Flukiger, P.; Luthi, H.P.; Portmann, S.; Weber, J.; Swiss Center for Scietific Computing: Manno, Switzerland, 2000-2002. (b) Portmann, S.; Luthi, H.P. Chimia, 2000, 54, 766-769.

[23] Sichla, Th.; Niewa, R.; Zachwieja, U.; Eßmann, R.; Jacobs, H. Z. Anorg. Allg. Chem., 1996, 622, 2074.

[24] Otieno, T.; Bond, M.R.; Mokry, L.M.; Walter, R.B.; Carrano, C.J. Chem. Commun., 1996, 37.

[25] Heater, S.J.; Carrano, M.W.; Rains, D.; Walter, R.B.; Ji, D.; Yan, Q.; Czernuszewicz, R.S.; Carrano, C.J. Inorg. Chem., 2000, 39, 3881.

[26] Grant, C.M.; Stamper, B.J.; Knapp, M.J.; Folting, K.; Huffman, J.C.; Hendrickson, D.N.; Christou, G. J. Chem. Soc. Dalton Trans., 1999, 3399.

[27] Kanamori, K. Coord. Chem. Rev., 2003, 237, 147.

[28] Bond, M.S.; Czernuszewicz, R.S.; Dare, B.C.; Yan, Q.; Mohan, M.; Verastegue, R. Carrano, C.J. Inorg. Chem., 1995, 34, 5857.

[29] Kanamori, K.; Ookubo, Y.; Ino, K.; Kawai, K.; Michibata, H. Inorg. Chem., 1991, 30, 3832.

[30] Czernuszewicz, R.S.; Spiro, T. G. In Inorganic Electronic Structure and Spectroscopy, Vol. 1; Solomon, E.I., Lever, A.B.P. Eds.; Wiley-Interscience: New York, 1999; pp. 353-442.

[31] Mahroof-Tahir, M.; Keramidas, A.D.; Goldfarb, R.B.; Anderson, O.P.; Miller, M.M.; Crans, D.C. Inorg. Chem., 1997, 36, 1657.

[32] Shannon, R.D. Acta Cryst., 1969, 32A, 751.

[33] Dunitz, J.D.; Orgel, L.E. J. Chem. Soc., 1953, 2594.

[34] Campbell, J.R.; Clark, R.J.H. J. Chem. Soc. Faraday Trans. II, 1980, 76, 1103.

[35] Clark, R.J.H.; Franks, M.L.; Turtle, P.C. J. Am. Chem. Soc., 1977 , 99, 2473. 